\title{
DESIGN AND ANALYSIS OF HIGH VOLUME LOW SPEED FAN (HVLS) FOR ROOM SIZE 24M X24M X 18M X
}

\author{
Pushpesh Singh \& Gajendra Vasantrao Patil \\ Department of Mechanical Engineering, Pillais HOC college of Engineering and Technology, University of \\ Mumbai, Khalapur, HOC Colony Road, Taluka, Rasayani, Maharashtra, India \\ Department of Mechanical Engineering, Pillais HOC college of Engineering and Technology, University of \\ Mumbai, Khalapur, HOC Colony Road, Taluka, Rasayani, Maharashtra, India
}

\begin{abstract}
Fans are playing a major role around the globe for effective and pocket friendly cooling, especially in the region of Asia where humidity is high. Thermal comfort being one of the most important factors for improvement in working environment for better quality of work. Moving of air around the body helps sweat evaporation and makes body feel comfortable. Mixing of air from top to bottom of the area so as to neutralise the change in temperature is done by fans effectively than any other means. Desertification of air is the biggest problem faced in any enclosed area which can be rectified by using fans. HVLS fans are one of the effective ways of moving air in bigger spaces like big warehoused, railway stations, hotels, offices and many more. They are one of the major contributors of improving quality of work in a workplace. Study of air movement caused by the existing traditional fans and comparing it with the larger HVLS fans in the same area results in using HVLS fans for bigger spaces. High volume low speed fans generate larger column of air and horizontal floor jets resulting in thermal comfort in the vicinity. Designing and simulating the ceiling and HVLS fans to know the air movement caused by them virtually. Considering the optimum design parameters for the best thermal comfort and comparing the results with the real tools outside in the world.
\end{abstract}

Keywords: Ansys; Computational Fluid Dynamics; Solid Works; Fluent; Airflow Simulation; Computer Aided Design

Received: Jun 08, 2020; Accepted: Jun 28, 2020; Published: Sep 14, 2020; Paper Id.: IJMPERDJUN20201213

\section{INTRODUCTION}

Fans are playing an important role in providing thermal comfort at low cost in various parts of world. (Ankur Jain, 2004) Ceiling fans are considered one of feasible solution to get a breeze of air for small spaces like residential apartments but in case of industrial warehouse or big space, requirement of bigger fans takes the lead to provide comfort.

Individuals feel inconvenience when someone sweats in a room space with air present in a room. Subsequently, individuals attempt to make air breeze around the bodies either normally or mechanically to upgrade body convective warmth exchange (Y. Anand, 2018). Air movement helps sweat vanishing and appropriately brings body comfort feeling. It is extremely troublesome for some individuals in developing nations to have an air conditioning system to accomplish the conditions suitable for indoor comfort (Y. Anand, 2018). The bigger fans namely High Volume Low Speed Fan (HVLS) are suitable for cooling working places of large size to increase comfort and productivity. A high volume low speed (HVLS) fan provides improved air circulation and thermal control in desired space by incorporating composite fan blades (Joe E. Madsen, 2011). The HVLS is like a hanging ceiling fan with bigger fan blades and motor. The blades rotate at a lower speed but due to large contact area a high volume of air columns is produced (Boyd \& Fairbank, 2001). 
HVLS fans are used in various places such as malls, barns, warehouses etc., due to its large blades its easily visible and it provides better air flow compare to other traditional fans in large areas. It leads in terms of thermal destratification (Bassiouny \& Korah, 2011) and energy consumptions in comparison to the traditional ceiling fans (Shultz \& Williams., 2007). Evaporative cooling is one of the cheapest ways to get thermal comfort (Y. Anand, 2018). The area of air movement by HVLS fan is higher than ceiling fans. Our objective is to conclude that ceiling fans are less efficient in large spaces than HVLS fans via CFD analysis. Simulations are carried out in a closed room with no furniture by a ceiling fan and then by a HVLS fan, comparing the airflows. Computational fluid dynamics is advanced in calculating the fluid flow directions with visual effects. Comparatively one HVLS can work more efficient than eight ceiling fans in the same space, providing more and gentle flow of air than ceiling fans by using less energy (Shultz \& Williams., 2007).

The demand of HVLS is increasing as more efficient fans are coming in market day by day with new innovation every time. Initially the HVLS fans are as big as 18 feet in diameter but now HVLS fans of 6 feet to 8 feet are performing well in comparatively small spaces (Bigassfans, 2014). As the evaporative cooling is cheap and efficient people are demanding HVLS fans as the thermal comfort in a place is more with less energy consumption.

\section{LITERATURE REVIEW}

After reviewing recent literature destratification of air in a closed room is a major point of study in fan industry. The project aims at designing and performing analysis on HVLS and traditional ceiling fans and to accumulate all forms of knowledge about HVLS model. Comparing the airflow of traditional ceiling fan with the HVLS fan in the enclosed space and determine the efficiencies in each case.

(Ankur Jain, 2004) studied the air movement around the fan blade by using smoke and detected that the fan efficiency is reduced by swirling of air around the tip and near the hub of the blades. The work done by the middle blade is $75 \%$ than the hub and tip side.

(Boyd \& Fairbank, 2001) investigated that how air conditioning and small fans are ineffective in large a warehouse and how the HVLS fan is more effective than both. (Joe E. Madsen, 2011) reviewed the HVLS fan by (Boyd \& Fairbank, 2001) and summarizes that airfoil design, blade angle, pitch angle plays an important role in efficiency of HVLS fan.

(Shultz \& Williams., 2007) presented the comparison of HVLS and LVHS fans in a barn for finding the effective way of cooling the cows in barn and increasing their thermal comfort, which results in better milk production.

From (Joe E. Madsen, 2011) and (Shultz \& Williams., 2007) it can be investigated that how ceiling fan and HVLS fans provide Air movement in a large space using CFD analysis which results in finding the optimum position and height of installation, which helps in reducing the cost for testing specimen. Design of HVLS fan to improve the airflow in a room, Analysis of existing airflow of ceiling fan in a room, Analysis of airflow around the HVLS fans, Finding the optimum design for both HVLS and ceiling fan, To perform possible outcomes comparing the results and establishing the relation of using HVLS fans for better efficiency in an enclosed space.

\section{DESIGN OF HVLS FAN FOR ROOM SIZE 24M X 24M X 18M}

HVLS fans are also ceiling fans but larger in diameter. These fans rotate at low speed and generate slow moving column of air. The moving column of air creates a gentle breeze of flow throughout the desired space resulting in natural evaporating cooling process. These fans produce large and constant horizontal floor jet. HVLS fans can be found in various size from 
feet diameter to 20 feet diameter depending upon the space required to circulate air. These fans are basically used in large spaces such as industries, malls, gymkhana etc. HVLS fans are more efficient than traditional ceiling fans when used in large areas. HVLS fans mainly consist of four to ten blades, hub and motor.

The Figure 1 depicts the visual of \#D model of HVLS fan designed in solidworks. The HVLS fans basically works on the principle of air Destratification and air mixing as the hot air being less dense move towards the ceiling and cold air being denser move towards the floor. Adequate mixing of hot air and cold air results in dropping down the temperature of the desired area and with the continuous movement of air a large horizontal jet is produced which collides with the walls and again moves back towards the HVLS fan.

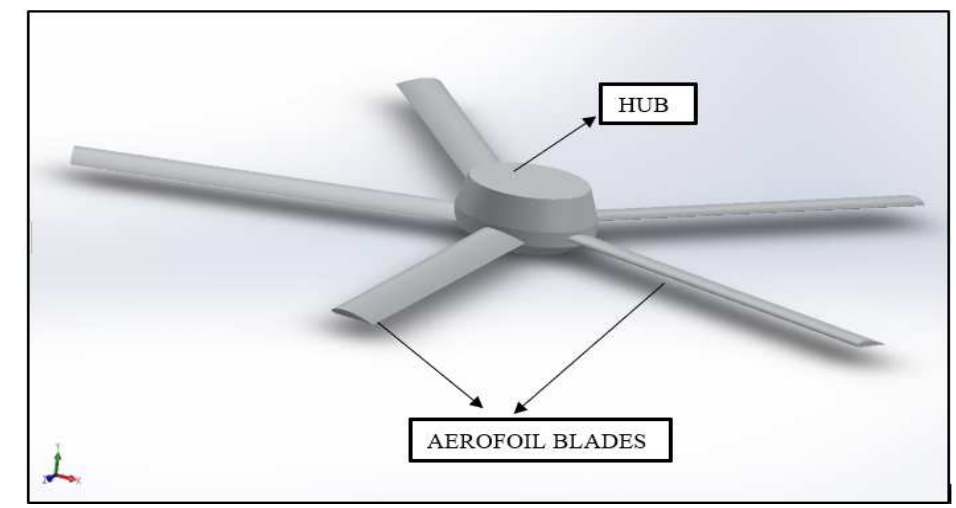

Figure 1: HVLS Fan (5 Blades).

\subsection{HVLS Fan Blade:}

Fan blade is basically in shape of aerofoil like an aircraft wing which is responsible for circulating air in region. There are various types of HVLS fan blades available in market with different aerofoil profiles but in our case, we have chosen three different profiles and finding the optimum profile for our HVLS fans. NACA 5414, NACA 6413, NACA 7415. After successful testing we have chosen NACA 6413 as the most optimum aerofoil profile for our HVLS fan. The material used for blade design is anodized aluminium.

The Figure 2 describes the nomenclature of selected aerofoil. There are symmetric and asymmetric aerofoils. Aerofoils used in fans are in nature of asymmetric. The aerofoil has a blunt leading edge and a pointed trailing edge along the aerofoil chord $(\mathrm{C})$.

The aerofoil has a convex upper surface with a maximum upper chamber of 13.3 percent of chord, occurring about 36 percent of chord from the leading edge. (Mishra2, 2014)

The aerofoil has a concave lower surface with a maximum lower camber of 2.4 percent of chord length, occurring bout 64 percent of the chord length from the leading edge.

Chord length of the aerofoil is usually taken between $150 \mathrm{~mm}$ to $400 \mathrm{~mm}$ (Bleier, n.d.) for different sizes of blades. Chord length effects the efficiency of fan by means of load on motor higher the chord length wider the span of aerofoil and more drag and due to which more load on motor. For optimum design consideration for a five blade HVLS fan we will consider the chord length to be $200 \mathrm{~mm}$. 


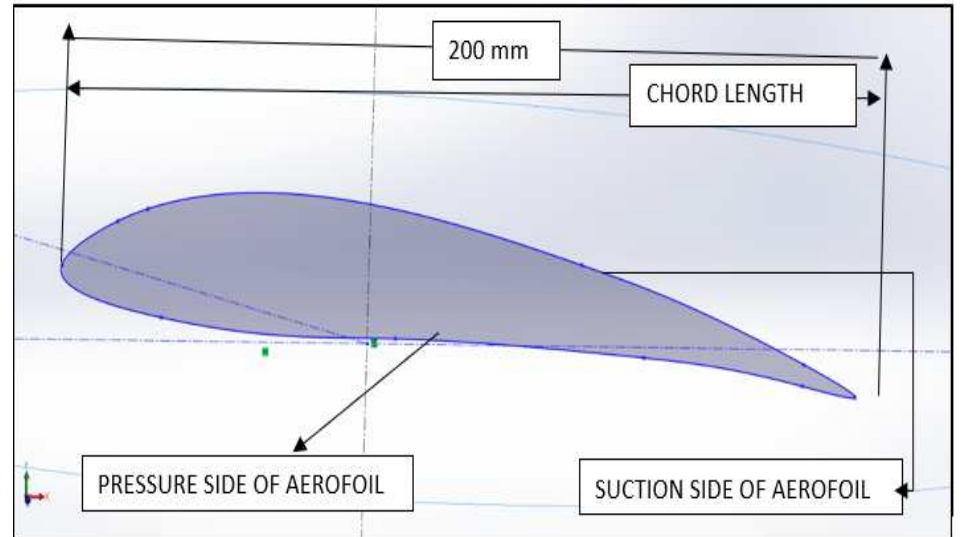

Figure 2: HVLS Asymmetric Aerofoil

\subsection{HVLS Hub:}

Shape and size of hub design effects largely on airflow. In case of HVLS fans there is no spacing between the hub and the blade due to connectors which can be seen in traditional fans. This results in large airflow beneath the fan as air recirculation towards the ceiling is close to negligible.

The Figure 3 describes about the Hub of HVLS fan as seen in Figure 4. The hub to tip ratio is reduced and the pitch of the fan is increased as the evenly distribution of load till the hub side. There are various companies using HVLS fans with connectors, but they make sure that the pitch angle is more towards the hub side so as the tip side which is moving faster than hub side does not carry more load. Evenly distribution of load due to lift and drag makes fan more efficient.

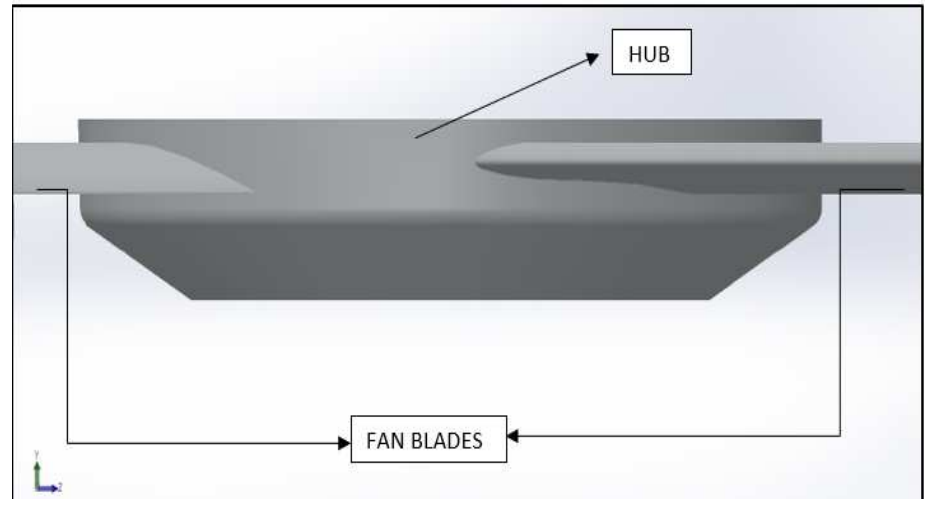

Figure 3: HVLS Fan Hub Side View.

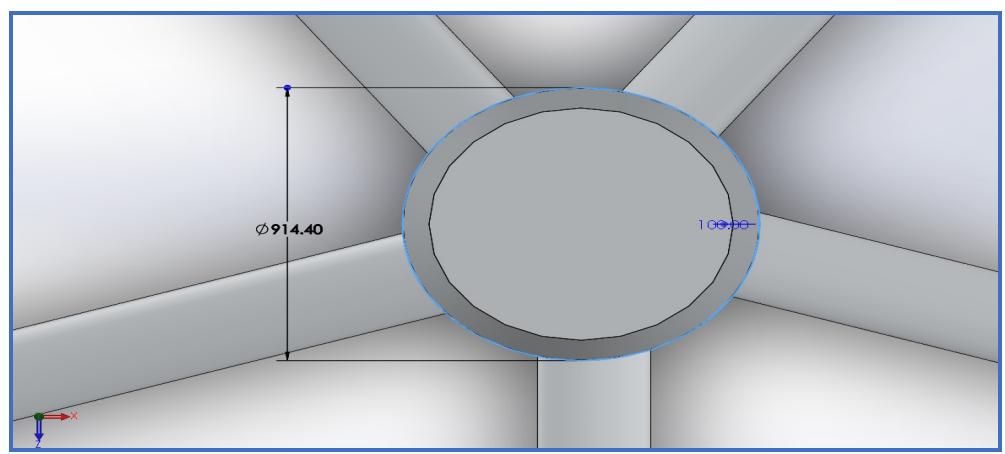

Figure 4: HVLS Fan 6m Diameter. 


\section{ANALYSIS OF HVLS FAN FOR ROOM SIZE 24M X 24M X 18M}

High volume low speed fans are gaining popularity due to its direct drive motors and the usage of these fans has been increased in many number and type of industries. From analysis point of view the geometry is simple from computational point of view. Complex geometry will result in more computational power, higher number of elements and probability if more scope for errors.

The HVLS Analysis Has Been Done In Two Scenarios,

- Selecting the type and number of blades for analysis.

- Effect of installation height on the operation of HVLS fans,

\subsection{First Scenario:}

To observe and conclude the effects of different number of blades with 4,5 and 6 blade configurations in the enclosed facility

\subsubsection{Method 1:}

Investigate the best case among three models with the NACA 5414, 6413 and 7415 aerofoils with the pitch angles of $12^{\circ}$, $12^{\circ}$ and $13^{\circ}$, respectively.

\subsubsection{Procedure:}

- The CFD simulations have been carried out using following manner: Steady-state assumption with multiple reference frame which is also known as the MRF technique

- Turbulence model applied: $\mathrm{k}-\varepsilon$ turbulence model.

- Simulation tool: STAR-CCM+ Version 8.04 (single integrated user interface) STAR-CCM+ is a complete multidisciplinary platform for the simulation of products and designs operating under real world conditions.

- Important consideration while designing:

- During a single revolution the volumetric air flow through the blade disc should not be less than 14 cubic meters

- The tip speed of the blade of the should not be greater than $27 \mathrm{~m} / \mathrm{s}$

\subsection{MODELLNG:}

The following geometry model has been created for simulation of HVLS fans. The geometry has been kept simple so as to reduce the computational power and the number of elements. The fan is placed in the centre of the specified room.

Room size $-24 \times 24 \mathrm{~m}$, Height of the room $-18 \mathrm{~m}$, the fan is assumed to rotate at RPM=60.

The following steps are to be followed in the modeller section of analysis, for better results the geometry should not be more complex so that while exporting it from any design software the multiple surface creations for the same part can be avoided. For Analysis of HVLS fan the geometry is first surrounded by the enclosures known as fluid domain under which the flow has to be calculated. 


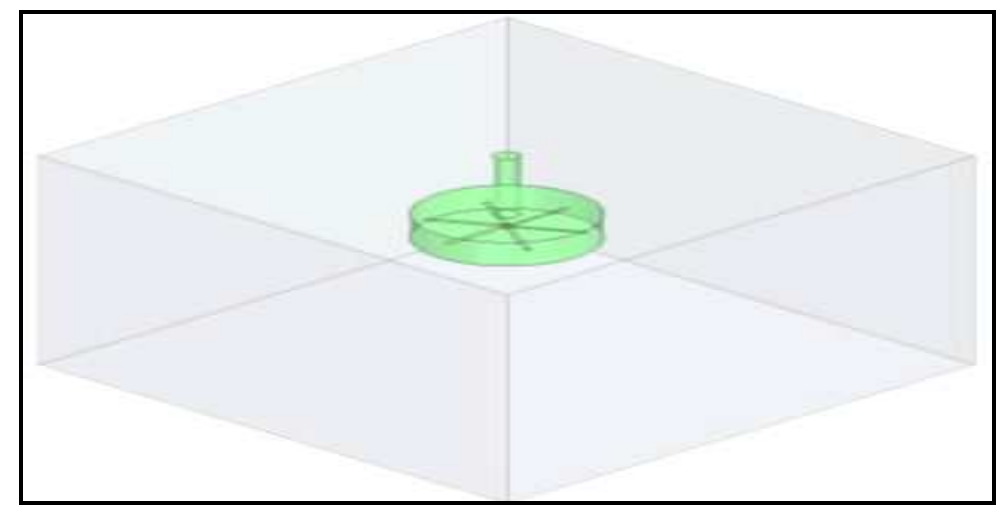

Figure 5: HVLS Fan with Geometry 3D View.

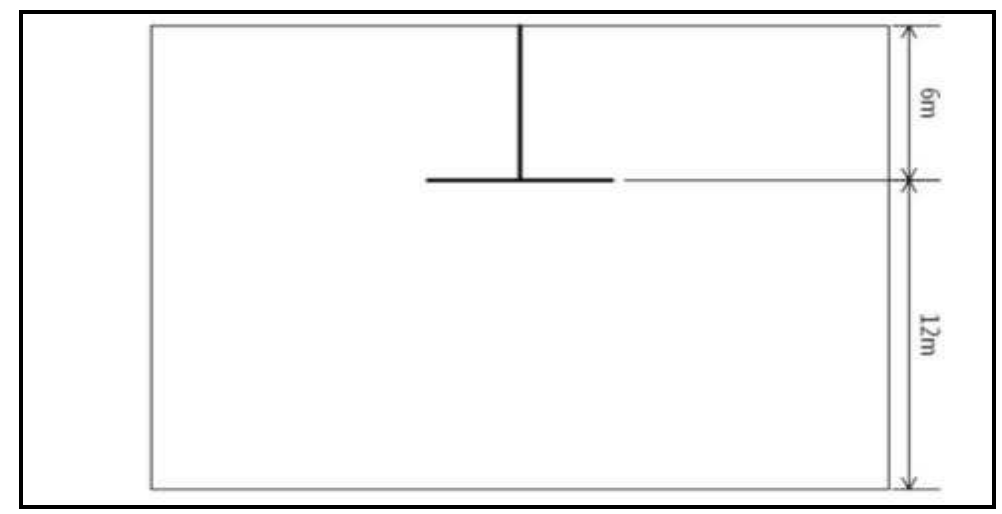

Figure 6: HVLS Fan with Geometry Front View.

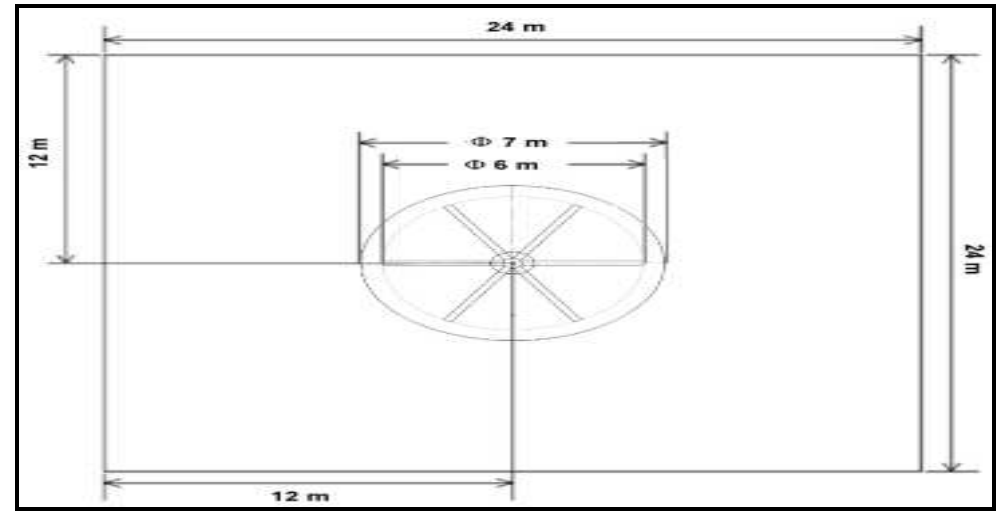

Figure 7: HVLS Fan with Geometry Top View.

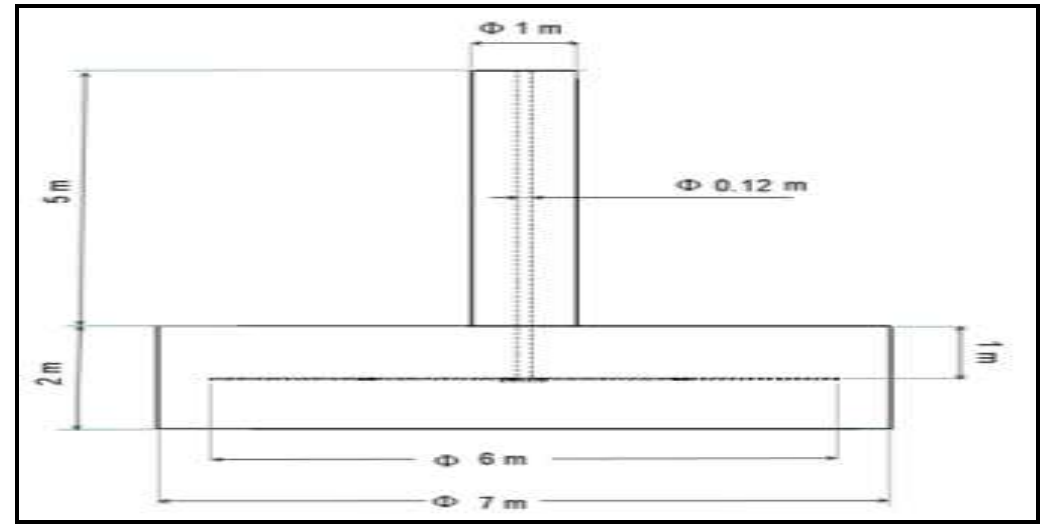

Figure 8: HVLS (High Volume Low Speed) Fan. 
4.3. Fluid Domain (Enclosures): There are two fluid domains in our design one is the room and another is fan enclosure. Enclosures can be of any shape depending upon the type of geometry, but the selected enclosure should be around the geometry enclosing it completely without any leakage or intersection between geometry and the enclosure. The room enclosure is basically the cuboid shape and the HVLS enclosure includes two cylinders one with the diameter of $7 \mathrm{~m}$ around the blades and other around the rod of dimensions $1 \mathrm{~m}$.

4.4. Boolean (Subtraction): Boolean operation is performed when the geometry is fully defined. It lets the software know about the contact regions in the domain and creating a cavity by subtracting the geometries. In our example the room being the cuboidal fluid domain will be subtracted from the cylindrical domains.

4.5. Name Selections: it is very important with respect to analysis as for the geometry to be user friendly its parts to be named properly, fan will be named as HVLS fan and cuboidal enclosure will be named as room. Naming can be done during meshing also.

\subsection{Aerofoil Selection for Blades:}

The most important part of HVLS fans is the profile of blades, the better the profile the more airflow we will get. The following are some of the aerofoil profiles from which we will select one for our optimum design consideration.

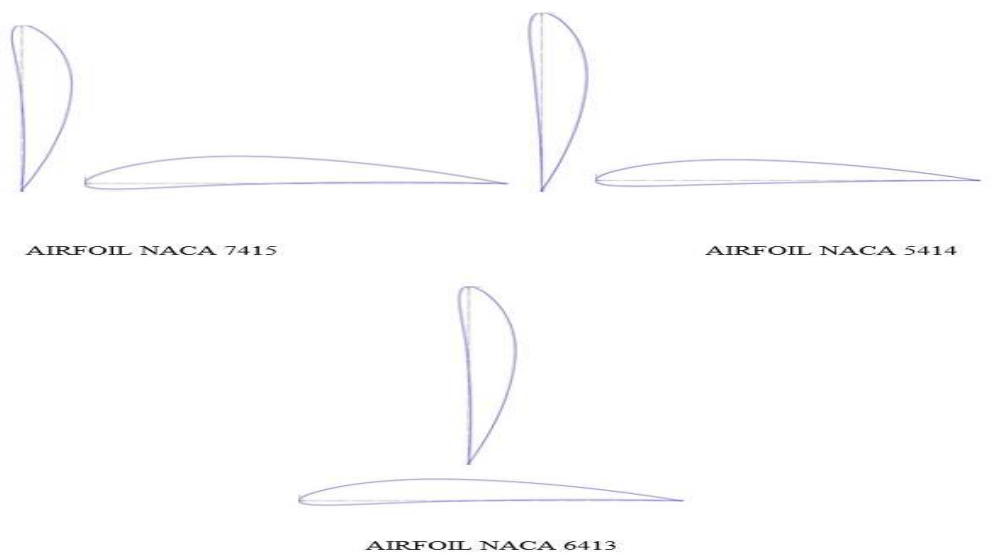

Figure 9: Aerofoil NACA 7415 Aerofoil NACA 5414 Aerofoil NACA 6413 Blade Designs [12].

Table 1: Mesh Details For Inner Domain

\begin{tabular}{|c|c|c|c|c|c|c|}
\hline Parameters & $\begin{array}{c}\text { Total } \\
\text { Thickness }\end{array}$ & $\begin{array}{c}\text { No. of Prism } \\
\text { Layer }\end{array}$ & Factor & $\begin{array}{c}\text { Max } \\
\text { Size(Mm) }\end{array}$ & $\begin{array}{c}\text { Minimum } \\
\text { Size(Mm) }\end{array}$ & $\begin{array}{c}\text { Surface } \\
\text { Growth Rate }\end{array}$ \\
\hline Top surface & - & - & - & 120 & 40 & 1.3 \\
\hline shaft & - & - & - & 100 & 20 & 1.3 \\
\hline blade & 30 & 8 & 1.3 & 10 & 5 & 1.3 \\
\hline hub & 30 & 8 & 1.3 & 15 & 8 & 1.3 \\
\hline tip & 30 & 8 & 1.3 & 1.5 & 0.5 & 1.3 \\
\hline
\end{tabular}

Three Models Shown In Figure Above Are NACA 5414, 6413 And 7415 With The Following Parameters:

- $\quad$ angle of pitch $-12^{\circ}, 12^{\circ}$ and $13^{\circ}$ respectively

- Diameter $-6 \mathrm{~m}$

- $\quad$ Chord length $-20 \mathrm{~cm}$

The above aerofoil profile has been selected as they have long and curved trailing edge for better air delivery. 


\subsection{Meshing}

Mesh independency test is done to reduce the dependency of geometry on number of cells, increasing number of cells does not conclude more precise results, it may also lead to high degree of error as the number of equations increase with the number of cells. So, balance between the number of finite elements and geometry size is to be maintained for robust design. The following tables includes the two domains one is inner domain which includes the HVLS fan and the outer domain which includes the room and the area around the HVLS fan.

After successfully defining the fluid domain and the adjoining design entities, now the entire geometry is taken into mesh modeller. In meshing the geometry is subdivided into small elements or cells and the whole simulation works cell to cell. Each sell contains 3-4 number of equations to be solved for continuity, momentum etc. After conducting mesh test which includes making geometry independent of mesh the following element sizes were taken for design consideration. The meshing type selected is polyhedral mesh as it gives better meshing of unequal surfaces with high degree of precision, a smaller number of bad elements and low aspect ratio.

The Mesh Is Polyhedral Mesh With 8 Prism Layers At The Blade Surface. By Applying the Mesh Setting From the Above Tables:

- Total number of cells in inner domain $=4.1$ million

- $\quad$ Total number of cells in outer domain $=1.1$ million

The Following Diagrams Illustrates the Mesh Generated by Applying Above Table Conditions

\subsection{Mesh Distribution at Domain Mid-Section:}

Figure 10 Shows as it can be seen from the above diagram that the mesh is denser near the fan zone so as to get higher precision in results. From blades to tip and from hub to shaft the polyhedral mesh have more cells or finite elements to get higher degree of precision with low residuals error.

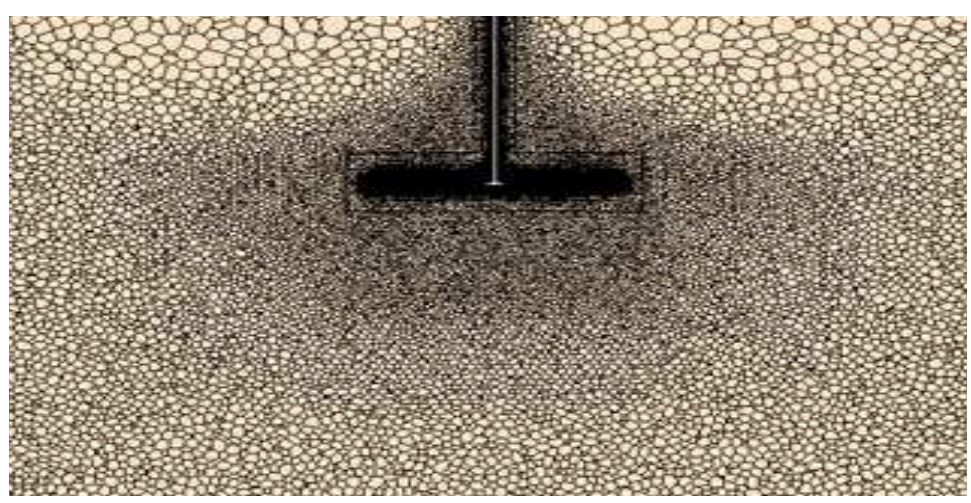

Figure 10: Mid-Section Mesh.

4.9. Blade Tip:

Figure 11 indicates that how around the blades structured mesh is used to decrease the number of bad elements and to get better results by decreasing number of equations to be solved by the solver. 


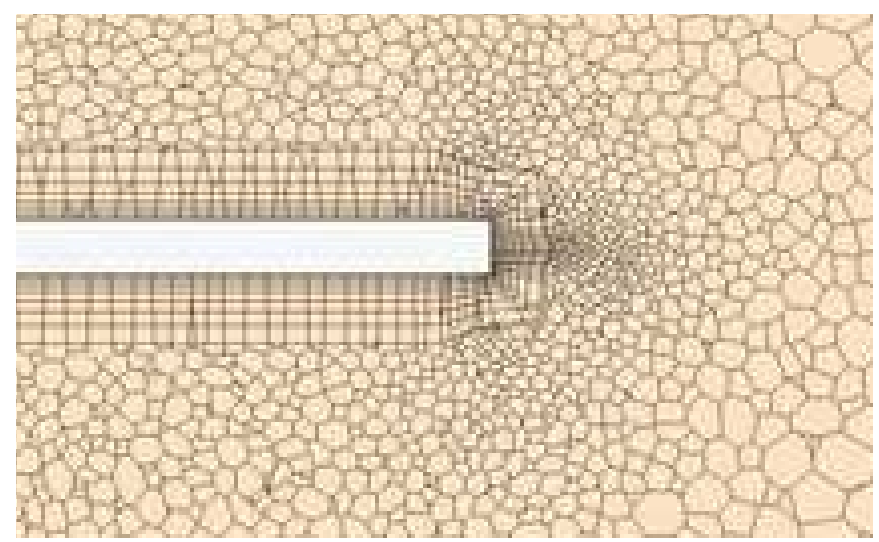

Figure 11: Blade Section Mesh.

\subsection{Around the Aerofoil:}

Figure 12 shows the prism mesh is used around the aerofoil blade with higher degree of inflation. Meshing with inflation simply increases the cells around the outer surface of aerofoil so as to get better results near surface. By using this analysis method better accuracy and the airflow around the blades can be attained.

Near the hub: Uniform meshing is done all around the HVLS fan fluid domain and very fine elements are used as the surface of the fan is reached.

Figure 13 shows to make a problem error free or with less error we have to make problem grid independent or mesh independent. It means that, to eliminate error due to coarseness of grid is to perform a grid dependence study. It is basically a successive refinement of an initial coarse grid until certain key results do not change.

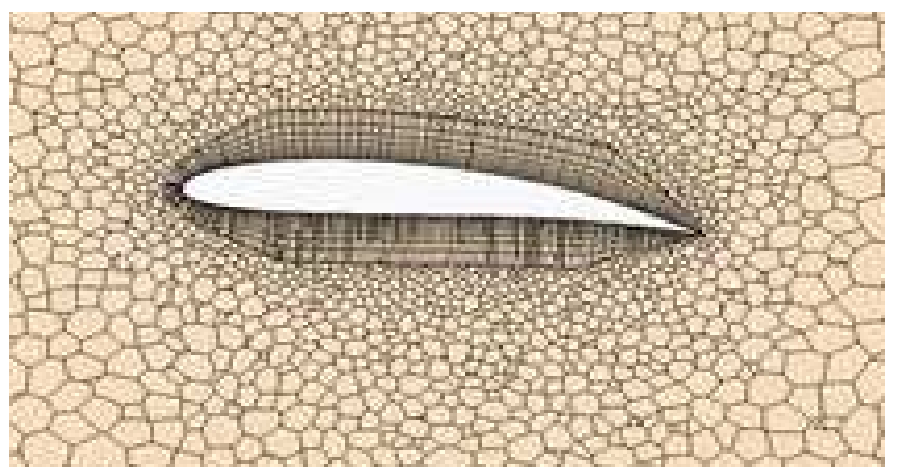

Figure 12: Aerofoil Mesh.

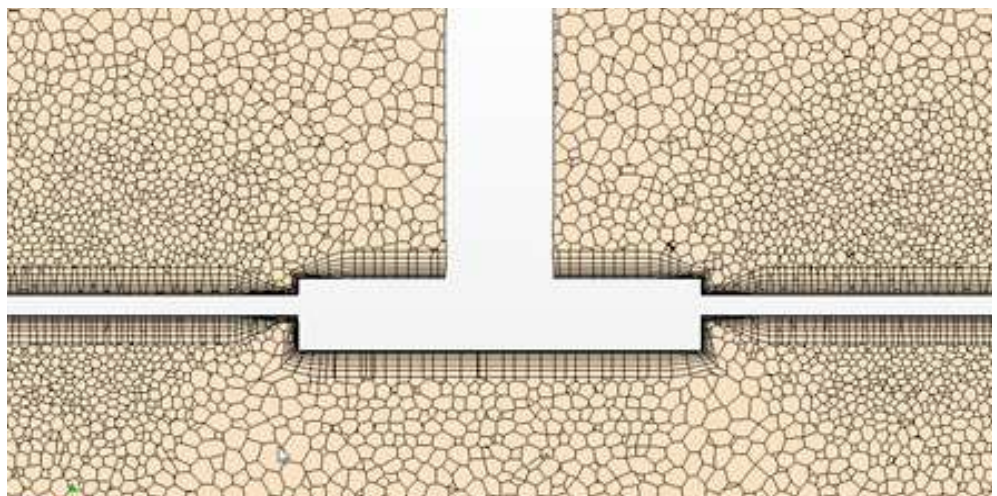

Figure 13: Hub Mesh. 


\subsection{Simulation:}

After meshing the geometry is imported to the solver where initial cell zone conditions and boundary conditions are defined to the solver. After 2000 iterations the solution is converged with residuals below $10^{-4}$. The lesser the residual errors range more robust is the solution. Balance between the number of cells and boundary condition values are to be maintained to get lesser discretization error. The following simulation has been performed by considering transient, pressure-based solver, turbulence K- $\square$ model with hybrid initialization.

\subsection{Turbulence Model:}

Simple and Untwisted blade configuration is considered as a proper model for this HVLS simulation.

K- $\square$ model used in this simulation distinguishes itself from standard model in 2 ways.

Those are

It contains new formulation for turbulent viscosity

For wall treatment in this model, there is option called 'all wall treatment' which is hybrid combination of both course and fine meshes.

The below figure shows Velocity magnitude and streamlines for the case with NACA 7415 with angle of pitch -13 degrees

Simulation of the Figure 14 indicates the streamlines and the velocity contour that the area below the rotor and also the area close to the wall $(\sim 3 \mathrm{~m})$ have high air recirculation. As the fan is pushing air downwards which results in higher magnitude of horizontal floor jet? Due to regular deflection of air from the surface results in more airflow around the surface and due to motor power, more velocity near the fan zone. The below figures indicate how the number of blades effect the velocity in an enclosed space

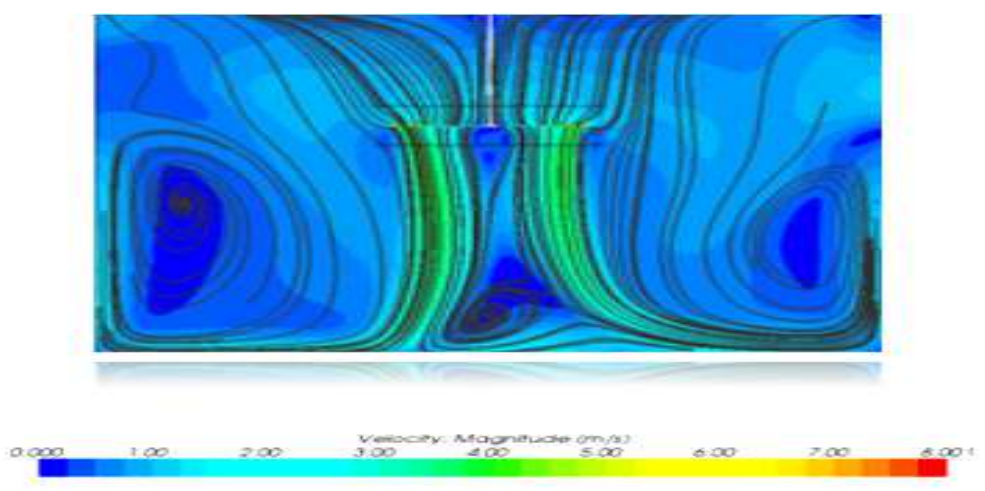

Figure 14: Velocity Streamlines NACA7415_13.

\subsection{Downward Velocity and the Magnitude for the Fan with Four, Five \& Six Blades}

The above three figures show that how the velocity profile changes around the fan and in an enclosure by increasing or decreasing the number of fan blades.

In a four-blade fan the magnitude of velocity is less and the area covered under the fan is uneven due to lack in continuously carrying the airflow in comparison to the six-blade fan where the column of air generated around the fan is even and velocity magnitude is also high. The results of the three models with NACA 5414, NACA 6413, NACA 7415 are show in the below Table 3 
The volumetric flow rate $(\mathrm{Q})$ show, the fan with the NACA 7415 generates the highest volumetric flow rate. However, from the aerodynamic point of view the blades of this HVLS fan undergo higher lift and torque values, and, hence, the HVLS fan with NACA 7415 needs more electrical power to be operated. Another criterion for the performance evaluation of HVLS fans is the effective area served by the fan in an empty enclosing (unobstructed space). As the protocols of HVLS fan suggest, the velocity of the generated air flow has to be measured at the heights of $100 \mathrm{~mm}, 1100$ $\mathrm{mm}$ and $1700 \mathrm{~mm}$ above the floor surface.

The table below presents the average of air velocity at the mentioned heights for all cases, in which the superiority of the case with NACA 7415 can be observed:

NACA 7415_ $13^{\circ}$ generates more airflow at different zones considered for measuring air velocity due to its pitch angle and chord length. As the trailing edge is facing more lift due to pitch angle so more power is required to overcome the lift and deliver air in the enclosed space.

Below comparison states that the assumptions we have taken while designing the HVLS fan are fairly close to the realistic design of fans around the globe. With the $6 \mathrm{~m}$ diameter fan at a speed of 60-70 rpm we can get a volumetric flow of $173-178 \mathrm{~m}^{3} / \mathrm{s}$ while consuming less power.

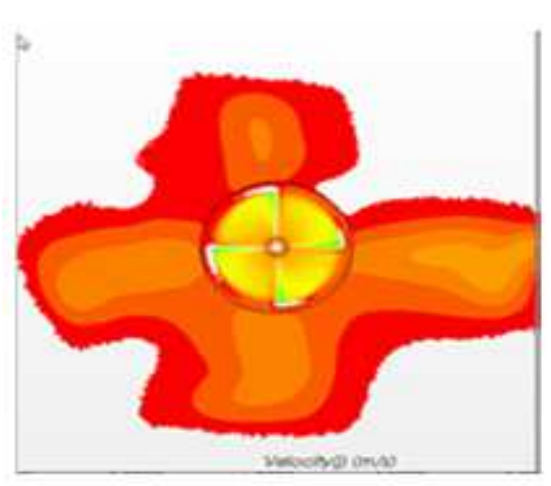

Four Blades

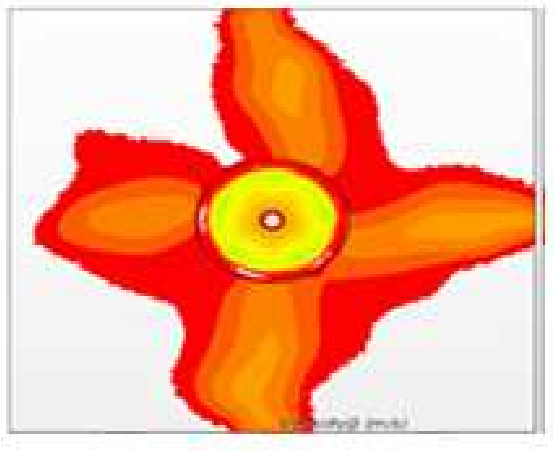

Five Blades

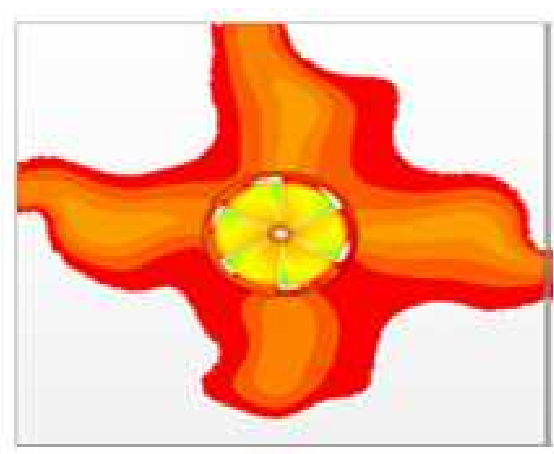

Six Blades

Figure 15: Four, Five Six Blade HVLS Fan Velocity Distribution Fan Velocity Distribution

Table 2: Comparison Between Performances of the HVLS Fans with Different Aerofoils

\begin{tabular}{|c|c|c|c|}
\hline Aerofoil pitch angle & Lift $(\mathbf{N})$ & Torque (N. m) & Velocity Flow Rate (Q) $\left(\mathbf{m}^{\mathbf{3}} / \mathbf{s}\right)$ \\
\hline NACA 5414_12 ${ }^{\mathbf{o}}$ & 163.7 & 80 & 149.2 \\
\hline NACA 6413_12 ${ }^{\mathbf{o}}$ & 174.5 & 90.2 & 164.2 \\
\hline NACA 7415_13 ${ }^{\mathbf{0}}$ & 200.6 & 104.8 & 174.3 \\
\hline
\end{tabular}

Table 3: Air Velocities Generated by Different HVLS Fans at Different Heights Above the Floor

\begin{tabular}{|c|c|c|c|c|}
\hline Type of HVLS & Diameter (m) & Speed (RPM) & Volumetric Flow Rate(m $\left.\mathbf{m}^{\mathbf{3}} \mathbf{s}\right)$ & Power (HP) \\
\hline Protav 5500 & 5.5 & $55-60$ & 135.0 & 2.2 \\
\hline Protav 6500 & 6.5 & $55-60$ & 89.7 & 2.2 \\
\hline GFAN61 & 6.1 & 67 & 137.8 & 1.5 \\
\hline NACA 7415_13 & 6.0 & 60 & 174.3 & 1.3 \\
\hline
\end{tabular}

\subsection{Blade Simulation:}

A study on aerofoil profile is conducted after selecting the adequate blade type. It is important to run a simulation on blade surface for pressure and velocity contours with given pitch angle. To view the airflow around the aerofoil an inlet velocity of $25 \mathrm{~m} / \mathrm{s}$ is considered over the surface. 
The leading edge of the aerofoil is blunt while the trailing edge is sharp, this is because as the flow is turbulent the drag forces increases abruptly. The deviation of relative velocity from tangential to condition results in increased turbulence and drag. Blunt leading edge also provides structural strength.

The area coloured in red denotes the high velocity zone and the area in green denotes the low velocity zone. From the above figure it can be seen that at the LE (leading edge) of aerofoil the velocity as less as the velocity decreases due to high drag. The velocity increases as the air in contact reaches from TE to LE on upper and lower section of aerofoil.

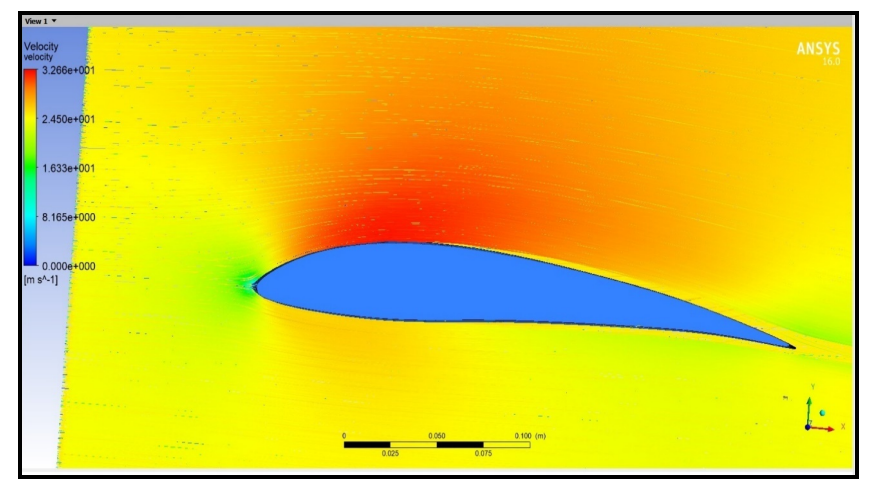

Figure 16: Velocity Streamlines around the Aerofoil.

\subsection{Effects of the Number of Blades:}

Downward velocity and the magnitude for the fan with four blades

The areas with downward flow shown in Figure 17 it is clearly visible that with an increase in number of the blades the downward area becomes wider. This results in a higher Q for the six-bladed model as presented in table below.

Table 6 shows that from the point of view of energy, the five-bladed HVLS fan requires the minimum aerodynamic torque for generating one unit of volumetric flow rate, which is a factor for optimum energy consumption.

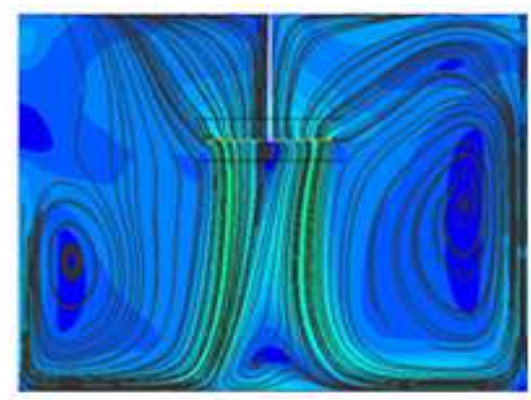

Four blades

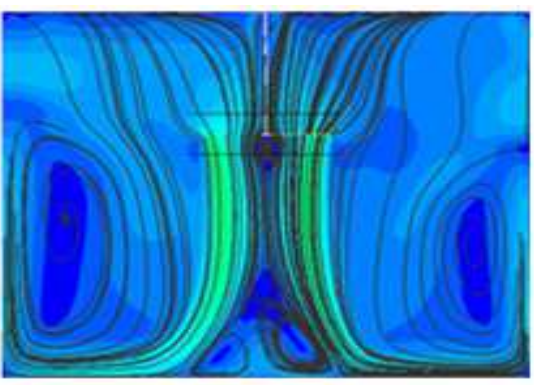

Five blades

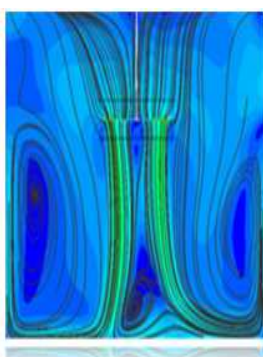

Six blades

Figure 17: Velocity Magnitude and Streamlines for the HVLS Fans with Different Number of Blades.

Table 5: Comparison between

Performances of the HVLS Fans With

NACA7415 $13^{\circ}$ with Different Number of

Blades

\begin{tabular}{|c|c|c|c|c|}
\hline $\begin{array}{c}\text { Number of } \\
\text { Blades }\end{array}$ & $\begin{array}{c}\text { Lift } \\
(\mathbf{N})\end{array}$ & $\begin{array}{c}\text { Torque } \\
(\mathbf{N}-\mathbf{m})\end{array}$ & $\mathbf{Q}\left(\mathbf{m}^{\mathbf{3}} / \mathbf{s}\right)$ & Q / Torque \\
\hline 4 & 155 & 88 & 153.4 & 1.74 \\
\hline 5 & 174.5 & 89 & 167.7 & 1.88 \\
\hline 6 & 200.6 & 104.8 & 174.3 & 1.66 \\
\hline
\end{tabular}


Table 6: Air Velocities Generated By NACA 7415_Aoa $13^{\circ}$ with Different Number of Blades at Different Heights

\begin{tabular}{|c|c|c|c|}
\hline Number of Blades & $\mathbf{1 0 0} \mathbf{~ m m}$ & $\mathbf{1 1 0 0} \mathbf{~ m m}$ & $\mathbf{1 7 0 0} \mathbf{~ m m}$ \\
\hline 4 & $1.49 \mathrm{~m} / \mathrm{s}$ & $1.0 \mathrm{~m} / \mathrm{s}$ & $0.74 \mathrm{~m} / \mathrm{s}$ \\
\hline 5 & $1.58 \mathrm{~m} / \mathrm{s}$ & $1.07 \mathrm{~m} / \mathrm{s}$ & $0.83 \mathrm{~m} / \mathrm{s}$ \\
\hline 6 & $1.79 \mathrm{~m} / \mathrm{s}$ & $1.15 \mathrm{~m} / \mathrm{s}$ & $0.86 \mathrm{~m} / \mathrm{s}$ \\
\hline
\end{tabular}

4.16. Second Scenario: Effect of the Installation Height and the Location on HVLS Performance:

After successful study of how number of blades affect the performance of the HVLS fan, the study of how the installation height and the placement of fan in an enclosed space effects its performance.

For simplicity of the problem same mesh is used for simulation.

\subsection{Installation height effect:}

The HVLS considered here is to be mounted at the centre of the room at different height. The value of $\Delta \mathbf{h}=\mathbf{0}$ is considered to be as the baseline case and other three cases are simulated. $(\mathrm{H}=0.1 \mathrm{~m}, 1.1 \mathrm{~m}$ and $1.7 \mathrm{~m}$ ) For evaluation volumetric flow rate (Q), aerodynamic lift (L) and Torque are considered.

Figure 18 Shows it can be studied that how the installation height is affecting the airflow around the enclosed space. As the height of the fan is decreasing from the baseline, less amount of air is pushed below the fan. The region below the fan has low air flow and the region above the fan gets more air at the suction.

As the height decrease the desertification factor also decreases which results in high temperature on the ceiling. As the fan decreases above the baseline the desertification factor increases but due to less area of suction the mixing of air above the fan if low which again results in uneven temperature distribution around the enclosed space. From above figures it can be stated that how the height of fan is important while selecting an HVLS fan.

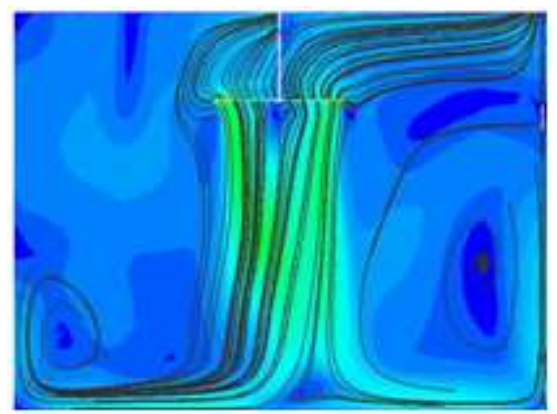

$h=+2 m$

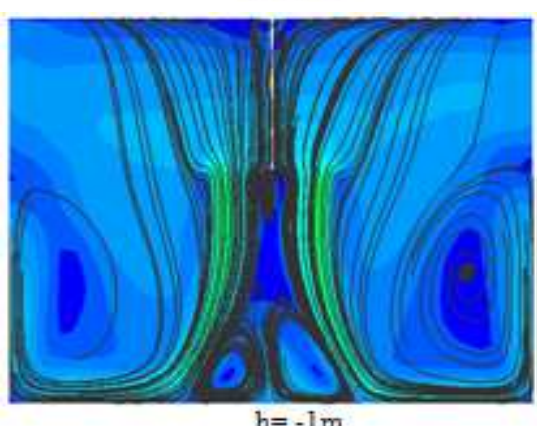

$\mathrm{h}=-1 \mathrm{~m}$

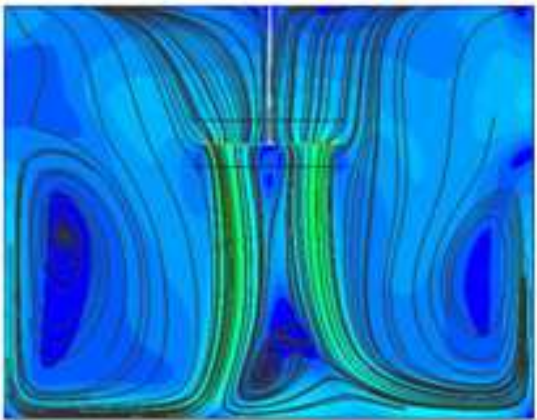

$\mathrm{h}=0 \mathrm{~m}$ (baseline)

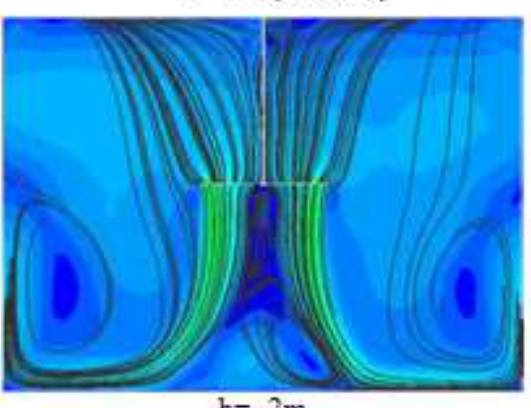

$h=-2 m$

Figure 18: Velocity Magnitude and Streamlines at Different Heights for the NACA 741513. 
Table 7: Performance of HVLS at Different Heights

\begin{tabular}{|c|c|c|c|}
\hline & $\mathbf{L}(\mathbf{N})$ & $\mathbf{T}(\mathbf{N} . \mathbf{m})$ & $\mathbf{Q}\left(\mathbf{m}^{\mathbf{3}} \mathbf{s}\right)$ \\
\hline$\Delta \mathrm{h}=+2 \mathrm{~m}$ & 216.2 & 108.1 & 138.8 \\
\hline$\Delta \mathrm{h}=0 \mathrm{~m}$ (baseline) & 200.6 & 105 & 174.3 \\
\hline$\Delta \mathrm{h}=-1 \mathrm{~m}$ & 197.5 & 105.5 & 168.1 \\
\hline$\Delta \mathrm{h}=-2 \mathrm{~m}$ & 194.2 & 106.1 & 140.3 \\
\hline
\end{tabular}

Table 8: Comparison between the Air Velocities

Generated by the HVLS Fan at Different Heights

\begin{tabular}{|c|c|c|c|}
\hline & $\mathbf{H}=\mathbf{0 . 1} \mathbf{~ m}$ & $\mathbf{H}=\mathbf{1 . 1} \mathbf{~ m}$ & $\mathbf{H}=\mathbf{1 . 7} \mathbf{~ m}$ \\
\hline$\Delta \mathrm{h}=+2 \mathrm{~m}$ & $1.7 \mathrm{~m} / \mathrm{s}$ & $1.04 \mathrm{~m} / \mathrm{s}$ & $0.79 \mathrm{~m} / \mathrm{s}$ \\
\hline$\Delta \mathrm{h}=0 \mathrm{~m}$ & $1.75 \mathrm{~m} / \mathrm{s}$ & $1.15 \mathrm{~m} / \mathrm{s}$ & $0.86 \mathrm{~m} / \mathrm{s}$ \\
\hline$\Delta \mathrm{h}=-1 \mathrm{~m}$ & $1.83 \mathrm{~m} / \mathrm{s}$ & $1.06 \mathrm{~m} / \mathrm{s}$ & $0.82 \mathrm{~m} / \mathrm{s}$ \\
\hline$\Delta \mathrm{h}=-2 \mathrm{~m}$ & $1.60 \mathrm{~m} / \mathrm{s}$ & $1.13 \mathrm{~m} / \mathrm{s}$ & $0.87 \mathrm{~m} / \mathrm{s}$ \\
\hline
\end{tabular}

\subsection{Effects of Eccentricity:}

Downward velocity and the magnitude for the fan with four, five and six blades

From Figure 19 it can be illustrated that how the placing of fan in an enclosed space effects the flow of air. At the baseline the flow is evenly distributed as the fan is shifted towards one of the corners the flow rate decreases due to high drag from the walls.

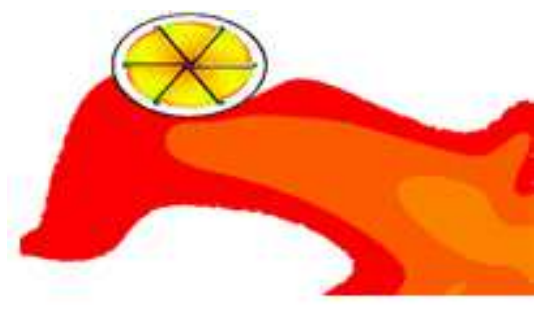

$\Delta \mathrm{x}=\Delta \mathrm{y}=4 \mathrm{~m}$

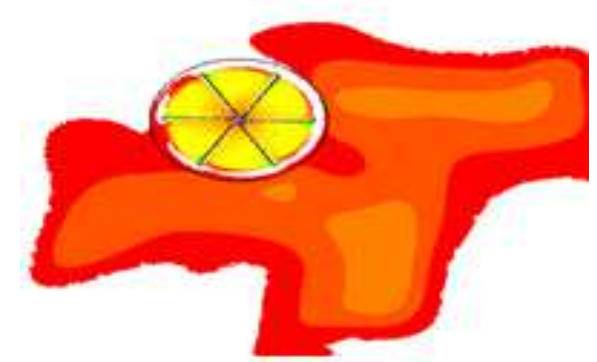

$\Delta \mathrm{x}=\Delta \mathrm{y}=2 \mathrm{~m}$

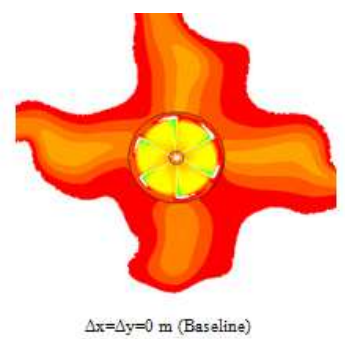

$\Delta x=\Delta y=0 m$ (Baseline)

Figure 19: Velocity Distribution of HVLS Fan at Different Horizontal Locations.

\subsection{Effects of Eccentricity:}

Here the fan is considered to be at the same height as of the baseline case. The fans are considered at different horizontal location at the room which is designated by $\Delta \mathrm{x}$ and $\Delta \mathrm{y}$.

Table 9: Comparison between the Performances the HVLS Fan at Different Horizontal Location

\begin{tabular}{|c|c|c|c|}
\hline & $\begin{array}{c}\mathbf{L} \\
(\mathbf{N})\end{array}$ & $\begin{array}{c}\mathbf{T} \\
(\mathbf{N} . \mathbf{m})\end{array}$ & $\mathbf{Q}\left(\mathbf{m}^{3} / \mathbf{s}\right)$ \\
\hline $\begin{array}{c}\Delta \mathrm{x}=\Delta \mathrm{y}=4 \\
\mathrm{~m}\end{array}$ & 218 & 111.5 & 159.4 \\
\hline $\begin{array}{c}\Delta \mathrm{x}=\Delta \mathrm{y}=2 \\
\mathrm{~m}\end{array}$ & 199.2 & 106.5 & 182.9 \\
\hline Baseline & 200.6 & 105 & 174.3 \\
\hline
\end{tabular}

Table 10: Comparison between the Air Velocities Generated by the HVLS Fan at Different Heights

\begin{tabular}{|c|c|c|c|}
\hline & $\mathbf{H = 0 . 1 ~ \mathbf { ~ }}$ & $\mathbf{H}=\mathbf{1 . 1} \mathbf{~ m}$ & $\mathbf{H}=\mathbf{1 . 7} \mathbf{~ m}$ \\
\hline$\Delta \mathrm{x}=\Delta \mathrm{y}=4 \mathrm{~m}$ & $1.32 \mathrm{~m} / \mathrm{s}$ & $0.9 \mathrm{~m} / \mathrm{s}$ & $0.66 \mathrm{~m} / \mathrm{s}$ \\
\hline$\Delta \mathrm{x}=\Delta \mathrm{y}=2 \mathrm{~m}$ & $1.39 \mathrm{~m} / \mathrm{s}$ & $1.05 \mathrm{~m} / \mathrm{s}$ & $0.81 \mathrm{~m} / \mathrm{s}$ \\
\hline
\end{tabular}




\begin{tabular}{|l|l|l|l|} 
Baseline & $1.75 \mathrm{~m} / \mathrm{s}$ & $1.15 \mathrm{~m} / \mathrm{s}$ & $0.86 \mathrm{~m} / \mathrm{s}$ \\
\hline
\end{tabular}

\section{ANALYSIS OF CEILING FAN FOR ROOM SIZE 24M X 24M X 18M}

Efficiency of HVLS fan can be determined by comparing it with the existing ceiling fans for the same room size. Ceiling fans have been used since decades as a mean to improve indoor thermal comfort. The fans produce an inexpensive way to cool the surrounding. Analysis can be done in following phases:

- Site description

- Modelling

- Meshing

- Simulation

- Validation

The above criteria will determine the airflow and efficiency of the fans in a room.

\subsection{Site Description}

The site which has been chosen is a room of size $24 \mathrm{~m} \times 24 \mathrm{~m} \times 18 \mathrm{~m}$ assuming there is no exchange of air from the surroundings. The ceiling fan is placed at centre of the room. Volume of room is $10368 \mathrm{~m}^{3}$.

\subsection{Modelling}

A 3D model has been created using Solid works with a following room size and fan size

- Length of Room: $24 \mathrm{~m}$

- Width of Room: $24 \mathrm{~m}$

- Height of Room: $18 \mathrm{~m}$

- Volume of Room: $10368 \mathrm{~m}^{3}$

- Fan Cylinder Diameter: $1.2 \mathrm{~m}$

- Fan Cylinder Height: $0.3 \mathrm{~m}$

- Volume of Fan Cylinder: $0.35 \mathrm{~m}^{3}$

Room is considered to be a closed volume without any inlet and outlet. The roof fan is solely considered to a momentum source.

For the analysis point of view the inner fluid domain will be considered as the flow of air will be in the inner side of the room. The fan will be considered as a cylinder with $1200 \mathrm{~mm}$ of diameter and $300 \mathrm{~mm}$ of height. As putting the actual fan for calculation will involve high computing power. The rotational zone involved 0.99 percent of the recreation field. 


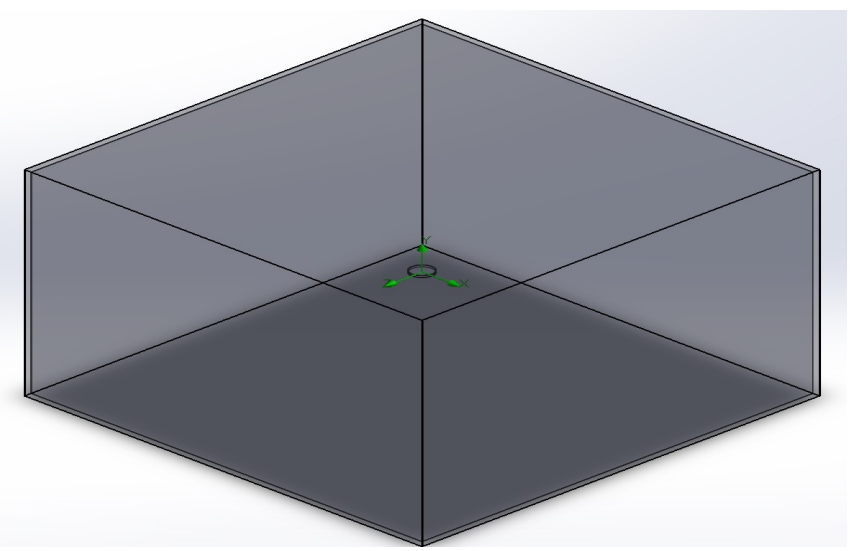

Figure 20: Ceiling Fan in a Room.

\subsection{Simulation}

After modelling and defining proper mesh the geometry is transferred to simulation software where the initial conditions of fan are defined with frame motion. Fifty thousand and above cells are considered for simulation. The cell zone condition defined were fan as 3D fan zone and the room as walls. Transient model with turbulent flow helps in finding the turbulent streamline flowing around the room. The fan is rotating at a speed of $370 \mathrm{rpm}$. Since there are no inlet and outlet in this simulation, the conservation target does not have any affect.

Figure 21 Shows it can be noted that the velocity below the fan is ranging from $2.5-3 \mathrm{~m} / \mathrm{s}$. The velocity is moving from red zone with highest velocity to the blue zone with comparatively low velocity. The region below the fan is getting maximum flow of air. The region between the fan and wall are less air as the air column produced by the ceiling fan is of lesser diameter which starts from the fan reaches the floor and then a horizontal jet is formed which moves till the walls. The circulation starts from fan and end at the floor. Below are results of airflow in a room at measured at different height, so that the flow around various regions in a room can be determined?

Figure 15 Shows it can be seen that for large room size the efficiency of ceiling fans to circulate the air is less that the HVLS fans. There is thermally stratified zone just few centimetres away from the fan zone.

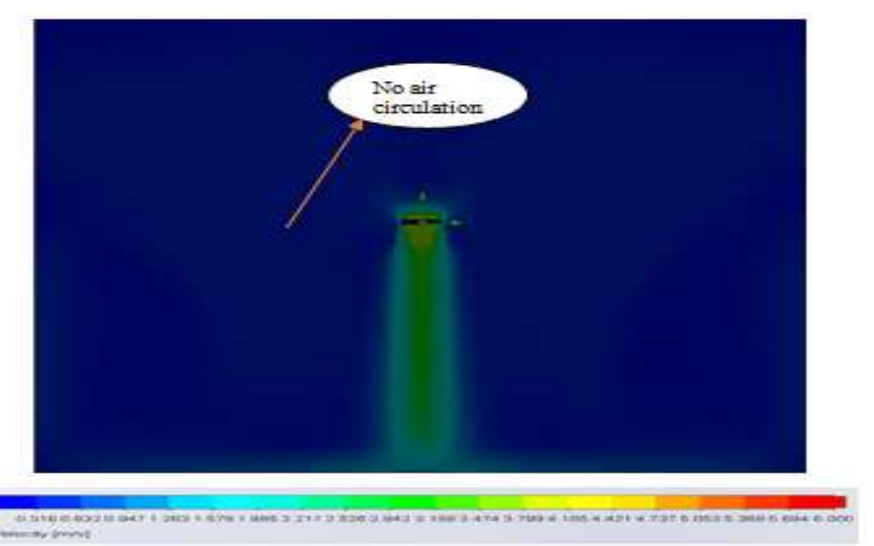

Figure 21: Velocity Streamlines around the Room. 


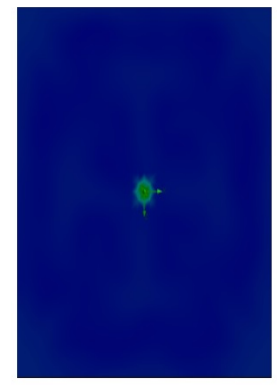

$1 \mathrm{~m}$ from fan

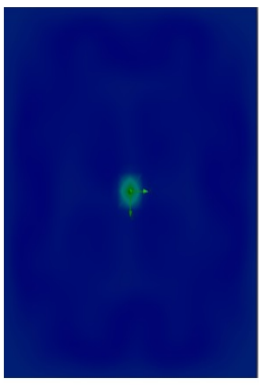

$3 \mathrm{~m}$ from fan

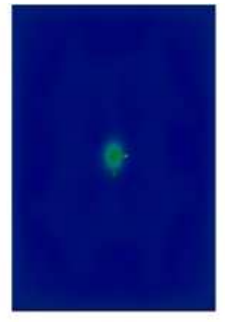

$6 m$ from fan

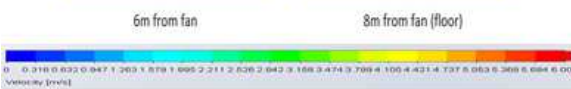

Figure 22: Velocity Flow at Different Levels of the Room.

\subsection{Validation}

It is a process in which the simulated results are compared with experimental results. For validation we have considered an anemometer (UA-965). For proper experimental results the doors and windows are closed so there is no inlet and outlet of air from the computational zone.

\section{RESULTS}

\subsection{HVLS Fan}

The CFD analysis analysed various parameters of airflow in room size $24 \mathrm{~m}$ x $24 \mathrm{~m}$ x $18 \mathrm{~m}$. It is observed that the HVLS fan is highly efficient than ceiling fans. To conclude this there were various test conducted which are explained below.

\subsection{First Scenario}

- By comparing the values of five blade model from the above Table 4, 5 with the values of NACA $6413 \_12^{\circ}$ from table 2, 3, it is observed that the two HVLS fans, one with five and the other with six blades, behave very similar to each other.

- This means that with an optimum design, one can considerably lighten the total weight of a HVLS fan. the streamlines and velocity magnitudes are presented in figure 18 are similar, here also the recirculation areas exist below the fan disc and near the side walls.

- Considering all the results and the geometrical parameters of fans and the enclosure, it shows that the HVLS fan based on NACA 7415 generates the highest volumetric flow rate (Q) and fastest air circulation in the enclosure.

- The comparison of four, five and six blades fan show that the fan with six blades has the highest volumetric flow rate and the fastest air circulation in the enclosure.

- While considering, the torque required per volumetric flow rate it is observed that the HVLS with five blades is the most efficient.

\subsection{Second Scenario}

- It can be concluded from table 9 and 10 that aerodynamic loads on the fan increase when the location of fan is close to the sidewalls,

- The velocity magnitudes diminish for the cases near the side walls, while the volumetric flow rate decreases.

- As the location of the fan gets higher, the area of the recirculation under the rotor gets smaller. 
- The lack of space and air behind the fan decreases the HVLS fan performance and increases the aerodynamic loads on the blades when the fan location is close to the ceiling.

- In case of the eccentricity the downward airstreams are not uniformly distributed. It is also shown that the aerodynamic loads on the blades increase for the eccentric installations

\subsection{Ceiling Fan}

With CFD analysis it can be observed that the ceiling fan in larger room is inefficient as it covers only 15 percent of the area under the fan. The rest of the blue region from figure 21 and figure 22 can be seen with negligible amount of airflow. Hence the person standing below the fan will only get adequate amount of breeze of air. The Horizontal jet generated is of low intensity because of height of fan.

As the fan is placed at a very low height from ceiling, there is less destratification of air which results in rise in temperature at the ceiling and hence less human comfort.

\section{COMPARISON OF CEILING FAN AND THE HVLS FAN}

From the CFD analysis done for ceiling fan and HVLS fan previously it is clear that for large spaces ceiling fan is ineffective compared HVLS fans for smooth airflow with large $\mathrm{cfm}$. The initial cost of the HVLS fan is higher than the existing traditional ceiling fan but in terms of operating cost, reliability and comfort for large spaces the HVLS fan takes the lead.

Table 11: Comparison of Ceiling Fan and the HVLS Fan

\begin{tabular}{|l|c|c|}
\hline \multicolumn{1}{|c|}{ Fan Type } & Ceiling Fan (4 Feet) & HVLS Fan (10 Feet) \\
\hline Power demand kW/fan & 0.074 & 0.4 \\
\hline Fan and install cost (Rupees) & $4000 /-$ & $200000 /-$ \\
\hline Fan run hrs/yr. & 4000 & 4000 \\
\hline energy cost / yr. @ 5 Rs. /kwh (Rupees) & $5920 /-(4$ fans) & $8000 /-$ \\
\hline Time to circulate air & 60 seconds & 17 seconds \\
\hline CFM/ fan & 8263 & 84000 \\
\hline Life cycle & Short & long \\
\hline
\end{tabular}

\section{CONCLUSIONS}

In this work, flow induced by the operation of ceiling fan and HVLS fan for a room has been studied. It can be concluded that the airflow generated by ceiling fan is not sufficient for cooling and destratification of room. The HVLS fan performs effectively for the region with high volumetric flow of air. The major shortcomings of the ceiling fans are placement of fans as well as size. By replacing it with HVLS the flow of air can improved. The major drawback of HVLS fans is the initial cost of product. The operating cost is much lower than the ceiling fans in numbers. Optimization of winglet and geometry could lead to further improvement in HVLS fan performance. Finally, the change in material and direct drive motors can be employed for future work on modelling and optimization.

\section{REFERENCES}

1. Alam, F., Chowdhury, H., Loganathan, B. \& Mustary, I., 2016. A Study of Aerodynamic Drag of Contemporary Footballs. Procedia Engineering, Volume 147, pp. 8186.

2. ALROBAIAN, ABDULRAHMAN A., SA KHAN, and MOHAMMED ASADULLAH. "A NEW APPROACH TO LOW-COST OPEN-TYPED SUBSONIC COMPRESSIBLE FLOW WIND TUNNEL FOR ACADEMIC PURPOSE." International Journal of Mechanical and Production Engineering Research and Development (IJMPERD) 8. 6, Dec 2018, 383-394. 
3. Anderson, J. D., n.d. In: computational fluid dynamics. s.l.:MCGRAW-HILL.

4. Anon., n.d. [Online] Available at: www.grc.nasa.gov.

5. Anon., n.d. [Online] Available at: www.airfoiltools.com.

6. Anon., n.d. [Online] Available at: http://etmpower.com/learn-more/technical-information/.

7. Anon., n.d. [Online] Available at: https://macroairfans.com/blog/.

8. Anon., n.d.fan size. [Online] Available at: https://www.delmarfans.com/educate/basics/what-size-ceiling-fan-do-i-need/.

9. Anon., n.d. HVLS fan. [Online] Available at: https://www.bigassfans.com/sg/fans/industrial/ceiling-fans/.

10. ansys, n.d. [Online] Available at: http://www.ansys.com/.

11. Aoki, K., Muto, K. \& Okanaga, H., 2010. Aerodynamic characteristics and flow pattern of a golf ball with rotation. Procedia Engineering, Volume 2, pp. 24312436.

12. Babich, F. et al., 2017. Transient three-dimensional CFD modelling of ceiling fans. Building and Environment, Volume 123, pp. 3749.

13. Bassiouny, R. \& Korah, N. S., 2011. Studying the features of air flow induced by a room ceiling-fan. Energy and Buildings, Volume 43, pp. 19131918.

14. Bleier, F. P., n.d. Fan Handbook. s.l.:s.n.

15. Bouche, D., Ghidaglia, J.-M. \& Pascal, F. P., 2011. Error estimate for the upwind finite volume method for the nonlinear scalar conservation law. Journal of Computational and Applied Mathematics, Volume 235, pp. 53945410.

16. Cadorin, M., Morini, M. \& Pinelli, M., 2010. Numerical analyses of high Reynolds number flow of high pressure fuel gas through rough pipes. International Journal of Hydrogen Energy, Volume 35, pp. 75687579.

17. Chilbule, C., Upadhyay, A. \& Mukkamala, Y., 2014. Analyzing the Profile Modification of Truck-trailer to Prune the Aerodynamic Drag and its Repercussion on Fuel Consumption. Procedia Engineering, Volume 97, pp. 12081219.

18. Chowdhury, H. et al., 2016. A Study of Dimple Characteristics on Golf Ball Drag. Procedia Engineering, Volume 147, pp. 8791.

19. Das, P. et al., 2013. Large Eddy Simulation of the Flow-Field around a Full-Scale Heavy-Duty Truck. Procedia Engineering, Volume 56, pp. 521530.

20. Das, R. C. \& Riyad, M., 2017. CFD Analysis of Passenger Vehicleat Various Angle of Rear End Spoiler. Procedia Engineering, Volume 194, pp. 160165.

21. Dhande, K. G., R. A. V. I. Mathur, and A. J. A. Y. Sharma. "Performance evaluation of a centrifugal blower of air assisted sprayer for orchard pesticide applications." International Journal of Agricultural Science and Research 6.4 (2016): 119130.

22. Gharbi, N. E., Absi, R., Benzaoui, A. \& Bennacer, R., 2011. An improved near-wall treatment for turbulent channel flows. International Journal of Computational Fluid Dynamics, Volume 25, pp. 4146.

23. GOVARDHAN, DASARI, A. KRISHNAIAH, and AVSSKS GUPTA. "DEVELOPMENT OF METHODOLOGY OF THE HEAT SINK THERMAL ASPECT FOR LOW COST EFFECTIVE CFD SOLUTIONS FOR REASONABLY HIGH QUALITY DESIGN." International Journal of Mechanical and Production Engineering Research and Development (IJMPERD) 8. 3, Jun 2018, 155160

24. Hassan, S. M. R., Islam, T., Ali, M. \& Islam, M. Q., 2014. Numerical Study on Aerodynamic Drag Reduction of Racing Cars. Procedia Engineering, Volume 90, pp. 308313. 
25. Hassanzadeh, R., Sahin, B. \& Ozgoren, M., 2011. Numerical investigation of flow structures around a sphere. International Journal of Computational Fluid Dynamics, Volume 25, pp. 535545.

26. Hassan, Mohammad Ul, and Sudarshan Singh. "Fabrication, Experimentation, Performance Evaluation of Two Stage Air Cooler and Comparison with Conventional Air Cooler." International Journal of Mechanical Engineering (IJME) 5.4 (2016): 7584.

27. Hetawal, S., Gophane, M., Ajay, B. K. \& Mukkamala, Y., 2014. Aerodynamic Study of Formula SAE Car. Procedia Engineering, Volume 97, pp. 11981207.

28. Ju, L. \& Du, Q., 2009. A finite volume method on general surfaces and its error estimates. Journal of Mathematical Analysis and Applications, Volume 352, pp. 645668.

29. Li, Y., Yan, C., Yu, J. \& Liu, H., 2017. A new high-accuracy scheme for compressible turbulent flows. International Journal of Computational Fluid Dynamics, Volume 31, pp. 362378.

30. Loyseau, X. F., Verdin, P. G. \& Brown, L. D., 2018. Scale-up and turbulence modelling in pipes. Journal of Petroleum Science and Engineering, Volume 162, pp. 111.

31. muhamadsujan, 2016. [Online] Available at: https://www.slideshare.net/muhammadshujan/cfd-ansys-fluent

32. Naruo, T. \& Mizota, T., 2014. The Influence of Golf Ball Dimples on Aerodynamic Characteristics. Procedia Engineering, Volume 72, pp. 780785 .

33. Piomelli, U., 2010. Large eddy simulations. International Journal of Computational Fluid Dynamics, Volume 24, pp. 391-391.

34. Potts, J. R. \& Masters, D., 2015. Validation of the Aerodynamic Loading on Basic Flying Disc Geometries Derived from CFD Simulations. Procedia Engineering, Volume 112, pp. 400405.

35. Shultz \& Williams., P., 2007. Electric power saving fan options for cow cooling.. 41st Annual Dairy Day. Anim. Sci. Dept., Univ. California,.

36. Singh, J. P., Kumar, S. \& Mohapatra, S. K., 2017. Modelling of two phase solid-liquid flow in horizontal pipe using computational fluid dynamics technique. International Journal of Hydrogen Energy, Volume 42, pp. 2013320137.

37. Singh, S. K. et al., 2017. Aerodynamic Analysis of a Two-Wheeler Rear View Mirror. Materials Today: Proceedings, Volume 4, pp. 90659071.

38. staff, e., 2012. [Online] Available at: https://www.edx.org.

39. users, w. m. a., 2010. [Online] Available at: https://www.engineeringtoolbox.com/.

40. Versteeg, H., n.d. AN introduction to CFD. In: s.l.:s.n.

41. wiki, n.d. [Online] Available at: https://en.wikipedia.org/wiki/Computational_fluid_dynamics. 